\title{
Skin Tissue Surface Morphology and Quality of RNA and Protein Extracted from Fresh and Stabilized Human Cleft Lip and Palate Tissue
}

\author{
Mohamad Shah Nurul Syazana ${ }^{{ }^{*}}$, Wan Azman Wan Sulaiman ${ }^{1}$, Ahmad Sukari Halim², Sulong Sarina ${ }^{3}$ \\ ${ }^{1}$ Universiti Sains Malaysia - Reconstructive Sciences Unit, Kubang Kerian, Malaysia; ${ }^{2}$ Universiti Sains Malaysia - School of \\ Medical Sciences, Kubang Kerian, Malaysia; ${ }^{3}$ Universiti Sains Malaysia - Human Genome Centre, Kubang Kerian, Malaysia
}

\begin{abstract}
Citation: Nurul Syazana MS, Wan Sulaiman WA, Halim AS, Sarina S. Skin Tissue Surface Morphology and Quality of RNA and Protein Extracted from Fresh and Stabilized Human Cleft Lip and Palate Tissue. OA Maced J Med Sci. $2014 \quad$ Mar 15; 2(1):23-28 http://dx.doi.org/10.3889/oamjms.2014.004 Key words: CL/P; fresh tissue; morphology; protein; RNA.

Correspondence: Mrs. Nurul Syazana Mohamad Shah. University Sains Malaysia Reconstructive Sciences Unit, School of Medical Reconstructive Sciences Unit, Schoolth Campus, Kubang Kerian Sciences, Health Campus, Kubang Kerian
16150,
Malaysia. 16150,

Received: 19-Nov-2013; Revised: 15-Jan2014; Accepted: 16-Jan-2014; Online first: 05-Mar-2014

Copyright: ๑ 2014 Nurul Syazana et al. This is an open-access article distributed under the terms of the Creative Commons Attribution License, which permits unrestricted use, distribution, and reproduction in any medium, provided the original author and source are credited.

Competing Interests: The authors have declared that no competing interests exist.
\end{abstract}

\begin{abstract}
Cleft lip palate is a human congenital disorder worldwide and the study of this genetic disease requires molecular genetic analysis. This analysis required the use of nucleic acid and protein, thus good quality and quantity of its extraction is important. We are comparing RNA and protein extractions from tissue biopsy of cleft lip palate in both fresh and stabilized condition. Tissue morphology was also captured using Scanning Electron Microscopy (SEM) for any morphology differences. Tissue homogenization may destroy nucleic acid stability but not its morphology. Low RNA concentration from stabilized tissue was found. However, there was no crucial issue of protein extraction, degradation or concentration. Tissue morphology was slight different between normal and $\mathrm{CL} / \mathrm{P}$ tissue.
\end{abstract}

\section{Introduction}

Orofacial clefts are the most common human congenital disorders that involve many genes and signaling pathways [1-4]. Cleft lip and palate (CLP) deformity has become a major public health problem affecting one in every 500 - 1000 births worldwide [5]. Two most common types of CLP are cleft lip with or without cleft palate and a cleft palate only [1]. This condition reflects a breakdown in normal embryological facial development which $70 \%$ affects the upper lip, the alveolar ridge, tooth eruption and palate fusion [6-7]. Another 30\% clefts are caused by monogenic syndromes or chromosomal aberrations [7]. This cleft lip and palate caused major psychosocial and economic burden for families and society that usually require surgical repair [8-9].

Recently, the work on human cleft lip and palate tissue has not been carried out widely. One study on tissues from CLP of Caucasian origin was obtained for the comparisons between the three types of cleft [10]. During the repair of CLP, the tissue biopsy that was taken out from the patients was found indispensable for genetic analysis. For this study, we aimed to optimize the best techniques for CLP tissue extraction and carried out further genetic testing later. Microscopic studies using Scanning Electron Micrsocopy (SEM) helps to figure out the fibre arrangements. Changes in skin morphology due to the CLP may give useful information in the skin proliferation process compared to the normal skin. SEM is beneficial in examining microscopic surface topography such as cells, hair, hair follicles, glands and blood vessels [11].

Several factors take place in order to maintain the stability of nucleic acids in the tissue such as the 
tissue storage, mass of tissue and the concentration. RNA is known as labile compared to DNA thus special care is required to prevent RNA degradation [12]. Immediate freezing of tissue specimens after surgery and further storage at $-80{ }^{\circ} \mathrm{C}$ serve as the standard procedure for the procurement of surgical specimens. Molecular profiles of cells may change start from removal from the patients, waiting for processing and processing procedures [13]. Requirement for effective yields is also based on the tissue mass. Different types of tissue require different mass of tissue in order to maximize the yields. In one study on bronchial tissue by Badrul Hisham $Y$ et al., 2011 have proved that high amount of the bronchial tissue have increased the RNA yields [14].Therefore, it is important to maintain the RNA integrity and its expression as it is believed to have significant effects to the results in gene expression studies later [15].

Different from RNA, obtaining good yields from protein extraction is not a critical issue. Protein profile in biological samples change significantly within the first few hours after sample harvesting which requires for immediate stabilization [16]. Stabilization either in $4{ }^{\circ} \mathrm{C}$ or $-20^{\circ} \mathrm{C}$ is relevant as to maintain the protein stability. Differ from blood, urine or stool sample, tissue specimen is always invasive and restricted to diagnostic or therapeutic procedures due to the risks of proteomic maintenance [17]. All molecule extraction methods require the homogenization or destruction procedures but time of homogenization might differ depends on the type of tissues [18] and type and volume of lysis buffer being used. Most studies on different tissue types have revealed that similar results were generated from unfixed fresh and fixed tissue for SDS-PAGE and Western Blot [18-20].

\section{Methods}

Tissue Morphology using Scanning Electron Microscopy (SEM)

Three normal and CLP skin tissue samples were collected from consented patients who underwent surgery in Hospital Universiti Sains Malaysia (HUSM). CLP tissues were obtained from CLP patients age between 3 months -17 years old who had CLP repair. Normal samples were obtained from normal patients who had a trauma or other surgical procedures between lip and nasal region. This study was approved by human ethics committee of University Sains Malaysia. The tissue samples were obtained at the area of surgery which is between the tip of nose and above the lip. The samples were cleaned with PBS to remove any blood or hairs from the tissues. Fixation process with glutaraldehyde and ethanol followed by incubation at $58{ }^{\circ} \mathrm{C}$ was done based on modifications by Periayah $\mathrm{MH}$ et al. [21].

Fixed tissues were then prepared on specimen stub and spurred with sputter-coated with gold for $3 \mathrm{~min}$ at $20 \mathrm{~mA}$ using Leica, SCD 005. Goldcoated specimens were then placed on the Scanning Electron Microscopy (SEM) (FEI, Quanta FEG 450) for image viewing.

\section{Tissue Selection}

Eight CLP tissues were obtained from consented patients. Tissue samples were divided into two groups: 4 fresh and 4 stabilized samples. Weight measurement was done based on two parameters; 30 $\mathrm{mg}$ and $100 \mathrm{mg}$. Each group was divided into these 2 parameters. Multiple repetitions (4-6 times) for each sample were done since large volume obtained at the final extraction.

\section{Tissue Storage}

Allprotect Tissue Reagent (Qiagen) was added to the tissue in order to stabilize the samples. For $30 \mathrm{mg}$ of tissue, $300 \mu \mathrm{l}$ of Tissue Reagent was used to submerge the tissue while for $100 \mathrm{mg}$ of tissue $1000 \mu \mathrm{l}$ of Tissue Reagent has been used. The tissues then were stored at $4{ }^{0} \mathrm{C}$ that can last for 6 months. After 1-2 months of storage, the preserved tissues were processed as described below.

\section{Tissue Processing}

The tissues then were minced and chopped into smaller pieces so that it can easily homogenize later. Fresh tissues were simultaneously added with Buffer RLT. Homogenization process was for every 5 min at full speed (1400 rpm) on ice and stop for every 1 minute interval by using homogenizer (Glas-Col). Further homogenization was required if the tissue was still incomplete. After that, the lysate was transferred to $1.5 \mathrm{ml}$ microcentrifuge tube and centrifuged the lysate at full speed $(13000 \mathrm{rpm})$ for $3 \mathrm{~min}$. The supernatant was carefully removed by pipetting and was transferred to an AllPrep DNA spin column placed in a $2 \mathrm{ml}$ collection tube.

\section{Total RNA Purification and Protein Precipitation}

RNA and Protein was extracted by using AllPrep DNA/RNA/Protein Mini Kit (Qiagen). The final expected RNA and protein yields were then stored at $20{ }^{\circ} \mathrm{C}$ prior to use. For protein, supernatant was used in downstream applications such as SDS-PAGE and Western Blotting later.

\section{Quantification of RNA}

RNA purity and concentration was determined using Infinite ${ }^{\otimes} 200$ PRO NanoQuant (Tecan). The concentration was measured at absorbance 260/280 $\mathrm{nm}$. Purity was determined by calculating the ratio of 
absorbance at $260 \mathrm{~nm}$ to absorbance at $280 \mathrm{~nm}$. Pure RNA has an $A_{260} / A_{280}$ ratio of 1.9-2.1.

\section{Determination of Protein Concentration}

A standard curve was prepared within the assay's working range using Pierce $660 \mathrm{~nm}$ Protein Assay (Thermo Scientific). Seven different standard values was used range between $125-2000 \mu \mathrm{g} / \mathrm{ml}$. The absorbance of standards and samples was measured at $660 \mathrm{~nm}$. Standard curve was prepared by plotting the average Blank-corrected $660 \mathrm{~nm}$ measurement for each BSA standard versus its concentration in $\mu \mathrm{g} / \mathrm{ml}$. Protein concentration for each samples were determined from the standard curve using the following equation:

$$
y=0.0006 x-0.011
$$

with $\mathrm{x}=$ protein concentration $(\mu \mathrm{g} / \mathrm{ml}), y=$ Absorbance of sample $(\mathrm{nm})$.

\section{Determination for Purity of Protein}

Purity of protein was determined by SDSPolyacrylamide Gel Electrophoresis (SDS-PAGE) followed by Coomassie Blue staining. This protocol was based on Lim CK et al. with minor modifications. Protein separation was done to ensure that the protein are well-separated by size and could approximate purity. The desired protein is between 25-37 kD.

\section{Statistical Analysis}

All the raw data were analyzed using SPSS version 20. Significant or non-significant differences were determined from non-parametric analysis, with $p$ value $<0.05$

\section{Results}

\section{Tissue Morphology using SEM}

Normal tissue was used as a control. Skin surface CLP tissue morphology of dermis and epidermis was visibly showed different features.

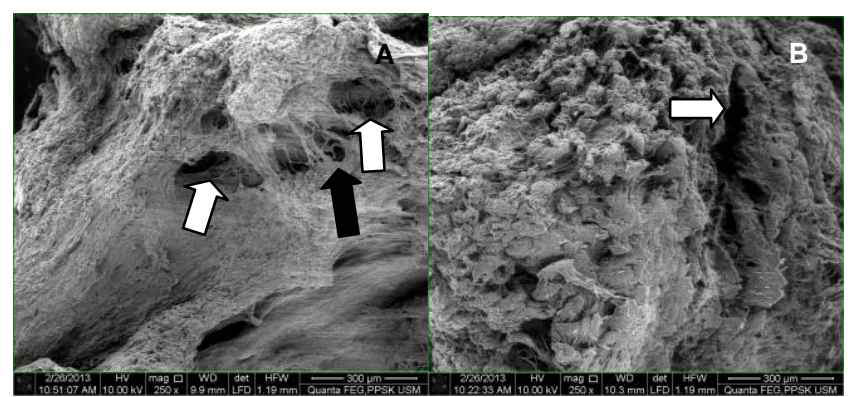

Figure 1: Scanning electron micrographs of human CLP tissue $A$ Fine surface morphology of epidermis with papillary layer (black arrow) and holes of hair shaft (white arrow). B) Abundant surface morphology of dermis with blood vessels holes (white arrow).Scale bar: $300 \mu m$, magnification: 250x.
The surface of dermis showed bulky appearance with lots of holes of blood vessels. This bulky contain collagen fibers, fibroblasts and blood vessels that support its integrity and elasticity. Meanwhile, the surface of epidermis showed clear and thin layer of appearance (Fig. 1).

In comparisons, at 1000x magnification, it has shown that lots of collagen fibers found on dermal of normal tissue compared to CLP tissue. Less collagen fibers and blood vessels holes can be seen on CLP dermal tissue (Fig. 2).

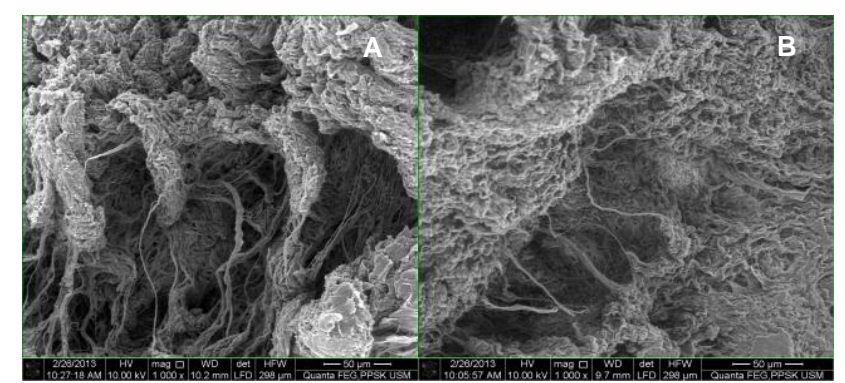

Figure 2 Scanning electron micrographs of human normal and CLP skin tissues from dermis layer. A) Pack collagen fibers with blood vessels holes in normal dermal skin. B) Less of collagen fibers and blood vessels holes found on human CLP skin compared to normal. Scale bar: $50 \mu \mathrm{m}$, magnification: 1000x.

\section{RNA Purity and Concentration}

Total RNA was determined from both fresh and stabilized tissue samples. All the samples showed good RNA purity in which fell between 1.89-2.1. From Table 1, it showed that $30 \mathrm{mg}$ fresh tissue samples had very low RNA yields as compared to the $100 \mathrm{mg}$ fresh tissue samples (Table 1).

Table 1: RNA purity and concentration were obtained from both fresh and stabilized tissue cleft samples with two different weight measurement.

\begin{tabular}{llccc}
\hline No. & $\begin{array}{l}\text { Type of } \\
\text { Samples }\end{array}$ & $\begin{array}{c}\text { Weight } \\
(\mathbf{m g})\end{array}$ & $\begin{array}{c}\text { Purity } \\
\mathbf{( 2 6 0 / 2 8 0} \mathbf{n m})\end{array}$ & $\begin{array}{c}\text { RNA Concentration } \\
\text { (ng/ /l) }\end{array}$ \\
\hline 1 & Fresh & 30 & 2.10 & 16.89 \\
2 & Fresh & 30 & 1.96 & 40.90 \\
3 & Fresh & 100 & 2.10 & 215.60 \\
4 & Fresh & 100 & 2.08 & 174.60 \\
5 & Stabilized & 30 & 2.10 & 87.21 \\
6 & Stabilized & 30 & 1.89 & 63.61 \\
7 & Stabilized & 100 & 2.08 & 53.29 \\
8 & Stabilized & 100 & 2.03 & 42.17 \\
\hline
\end{tabular}

In contrast, both $30 \mathrm{mg}$ and $100 \mathrm{mg}$ stabilized tissue samples showed low RNA yields with an average of 61.57 . However, as comparing $30 \mathrm{mg}$ fresh and stabilized tissue samples, the stabilized tissues have showed higher RNA yields than fresh tissue samples (Table 2).

From the Table 2A), it was found a significant difference for fresh tissue at different weight. Higher yields were significantly achieved when increased the volume of the fresh tissue samples compared to stabilized tissue. No significant difference was observed on stabilized tissue either low or high volume of samples were used. Table $2 \mathrm{~B}$ ) showed only significant difference between fresh and stabilized and fresh tissue at $100 \mathrm{mg}$. 
Table 2: RNA concentrations from fresh and stabilized tissue were analyzed based on two parameters. A) Compare by weight: 30 and $100 \mathrm{mg}$. B) Compare by type: Fresh and stabilized tissue.

\begin{tabular}{llll}
\hline & \multicolumn{2}{l}{ Weight $($ Mean \pm SD) } & \\
\cline { 2 - 3 } A) Type of Tissue & $30 \mathrm{mg}(\mathrm{ng} / \mu \mathrm{l})$ & $100 \mathrm{mg}(\mathrm{ng} / \mathrm{\mu l})$ & $\mathrm{p}$ Value \\
\hline Fresh & $34.38 \pm 11.68$ & $211.16 \pm 25.02$ & $\mathbf{0 . 0 2 1}$ \\
Stabilized & $43.17 \pm 38.75$ & $29.32 \pm 21.74$ & 0.564 \\
\hline
\end{tabular}

\begin{tabular}{|c|c|c|c|}
\hline \multirow[b]{2}{*}{ B) Tissue Weight (mg) } & \multicolumn{2}{|c|}{ Type of Tissue (Mean \pm SD) } & \multirow[b]{2}{*}{$\mathrm{p}$ Value } \\
\hline & Fresh $(\mathrm{ng} / \mu \mathrm{l})$ & 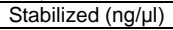 & \\
\hline 30 & $34.38 \pm 11.68$ & $43.17 \pm 38.75$ & 1.000 \\
\hline 100 & $211.16 \pm 25.02$ & $29.32 \pm 21.74$ & 0.021 \\
\hline
\end{tabular}

\section{Protein Concentration Determination from} Standard Curve and Protein Purity

The absorbance value of BSA standard was obtained from seven different concentrations of BSA standard (Fig. 3).

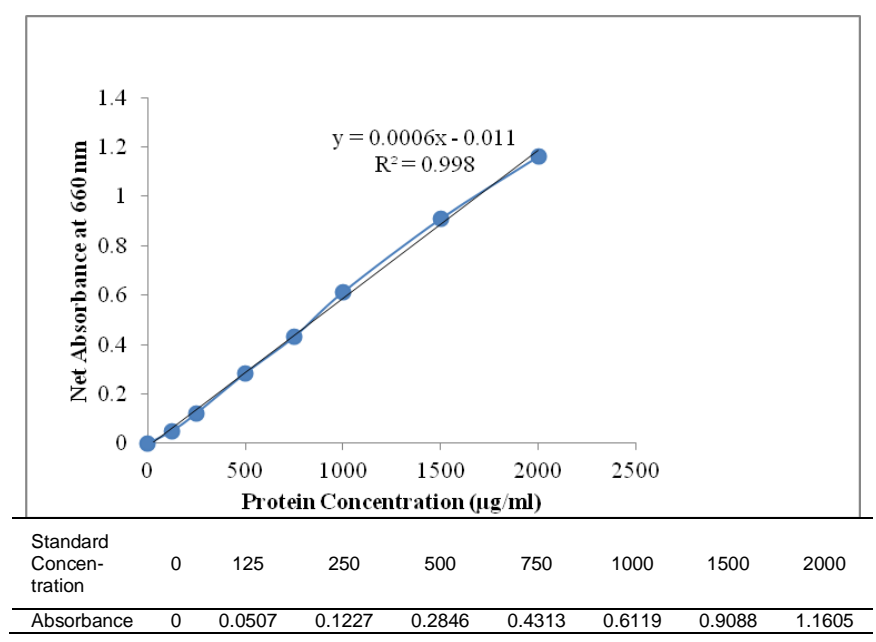

Figure 3 Standard curve was plotted (standard concentration versus absorbance value) with linear trend. Protein concentration from tissue samples were calculated using the displayed equation.

Standard curve with linear trend was plotted with the equation mentioned in the graph below. In our graph it showed that the $R^{2}=0.998$ means that the plotted graph was accurate and closely followed the straight line. From the standard curve, protein concentrations of all the tissue samples were calculated from the obtained equation.

Table 3: Both fresh and stabilized tissue cleft samples were determined for its protein concentration based on its absorbance value. Mean \pm SD was calculated from nonparametric analysis.

\begin{tabular}{clccccc}
\hline No. & $\begin{array}{l}\text { Type of } \\
\text { Samples }\end{array}$ & $\begin{array}{c}\text { Weight } \\
(\mathbf{m g})\end{array}$ & $\begin{array}{c}\text { Absorbance } \\
\text { Value }(\mathbf{6 6 0} \\
\mathbf{n m})\end{array}$ & $\begin{array}{c}\text { Protein } \\
\text { Concentration } \\
(\boldsymbol{\mu g} / \mathbf{m l})\end{array}$ & $\begin{array}{c}\text { (Mean } \pm \\
\mathbf{S D})\end{array}$ & P Value \\
\hline 1 & Fresh & 30 & 0.4792 & 817 & & \\
2 & Fresh & 30 & 1.1585 & 1949 & & \\
3 & Fresh & 100 & 0.3516 & 604 & & \\
4 & Fresh & 100 & 1.3095 & 2201 & 1421.63 & 1.000 \\
5 & Stabilized & 30 & 1.1936 & 2008 & \pm 662.87 & \\
6 & Stabilized & 30 & 1.1565 & 1946 & & \\
7 & Stabilized & 100 & 0.4566 & 779 & & \\
8 & Stabilized & 100 & 0.6302 & 1069 & \\
\hline
\end{tabular}
value $<0.05)$.

From the calculation showed on Table 3 , it was found that no significant different between fresh and stabilized tissue samples either using $30 \mathrm{mg}$ or
$100 \mathrm{mg}$ of tissue weight. Volume of the samples would not be the reasons to the variations of the protein concentrations values (Table 3 ).

Purity of both type of samples were observed. Both showed the protein was well-separated and the purity was determined by Coomassie Blue staining. It showed that the protein of interest could be qualitatively measured based on its size. The desired protein was at $30 \mathrm{kD}$ and only one band appear at this range (Fig. 4).

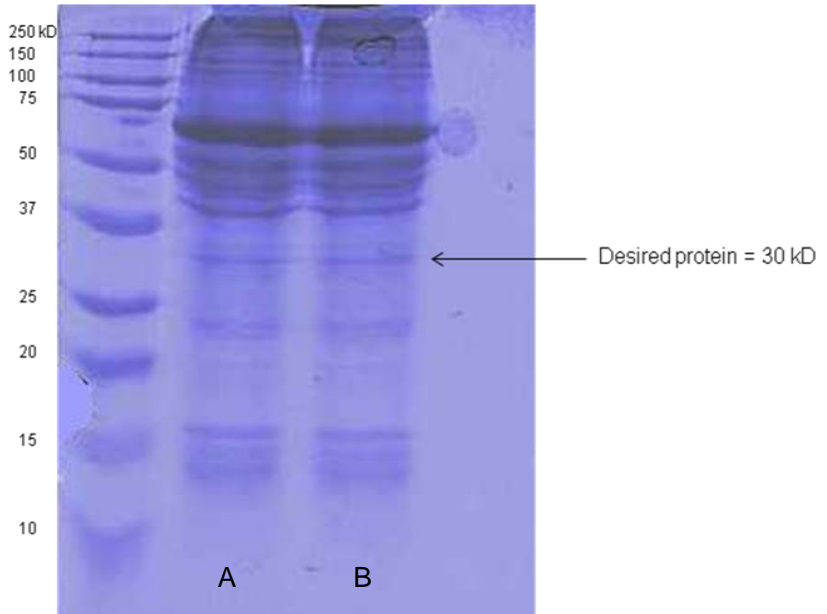

Figure 4: A) Fresh tissue B) Stabilized tissue. Protein separation and purity by SDS-PAGE followed by Coomassie Blue staining. The arrow indicates the protein of interest.

\section{Discussion}

\section{Skin Surface Tissue Morphology}

Different surface morphology between dermal and epidermal tissue skin from CLP patients (Figure 1) represents its different role and physiology in regulating skin structure. Fine structure of epidermal showed on the figure was its fine layer of the outer layer of skin. This layer can be one or more layers that functions to cover the surface of the body [23]. Furthermore, this lining does not contain collagen and fibers as the dermal layer. However, the exact surface structure is unclear with SEM, but it is most probably simple squamous epithelium.

It was believed that the fine layer structure in the epidermis most probably a papillary layer. It was supported by previous study which stated that papillary layer is an undulating form which is the layer of fine fibers of epidermis [24]. In addition, holes found on epidermal were likely the holes of hair shaft, not particularly the blood vessels holes that were found only on dermal layer. Dense CLP dermal skin proved the presence of fibroblasts, collagen and elastin fibers that made up its integrity and elasticity of skin. This part is compactly arranged in the superficial two-thirds which referred to as the mid zone of the dermis. It is characterized by the density of the fiber network, which is greater in the mid zone [24].

Comparing the dermal layer of normal and 
CLP at higher magnification (1000x) showing that both normal and CLP tissue were compactly arranged. However, dense fibers and blood vessels were significant in normal tissue compared to CLP tissue. Lack of fibers on CLP tissue best describes the reduced number of fibroblasts cells that synthesize protein collagen and thus reduced cell proliferation [25]. The decreased of cell proliferation can distort the growth of normal tissue formation at the lip area. Thus, it is proved that CLP tissue has changed from the normal formation.

\section{Extracted RNA and Protein from Different Tissue Condition}

Dermal morphology differences between normal and CLP tissue is essential to further investigate its gene regulation and expression quantitatively. Extracting RNA from the tissue considered to be a tough work as the RNA itself can easily degraded without proper handling. In this study, several optimizations and troubleshooting such as tissue mass, buffer lysis, and time of homogenization have been carried out to conclude the best findings. The RNA purity fell between 1.9-2.1 means that pure RNAs were obtained with the accurate values.

A significant increase of RNA yields in fresh tissue at $100 \mathrm{mg}$ has proven the significant used of larger volumes compared to low volumes of samples. Even though the exact protocol suggested using the tissue weight to not more than $30 \mathrm{mg}$, however we found that the recommended tissue weight did not suit with our samples. The major reason was the expected yield according to the kit protocol should be $>30 \mu \mathrm{g}$, but it was far behind for our samples to achieve to this level. Increasing the sample's volume has directly increased the quantity of RNA. Badrul Hisham $Y$ et al. have previously stated that increasing the amount of bronchial tissue starting material to $100 \mathrm{mg}$ improved the RNA yield as compared to the use of $30 \mathrm{mg}$ of starting material even though this amount of the tissue exceeds that recommended by the RNeasy Mini Kit Protocol [14].

By using Allprotect reagent, tissues became hard and thus increased the time for disruption and homogenization process to complete. However, Mutter GL et al. has described that storage of fresh tissue up to 72 hours in RNALater at room temperature did not introduce any bias to RNA expression [28]. It means that RNALater did not affect the RNA yields. In addition, the deterioration of tissue is dependent on time and temperature. The current recommendation is to allow a maximum of 24 hours at $4^{\circ} \mathrm{C}$ between surgery and processing [27]. It was crucial to have good quality of RNA yields since molecular methods usually required about $1 \mathrm{\mu g}$ of RNA for analysis. In our case, using fresh tissue was better than stabilized tissue to get higher yields of RNA. However, these different findings have suggested two possible reasons either type of samples or type of stabilizer affects the RNA yields. In addition, the involvement of degradation enzymes may possible.

Controlling time of homogenization and adequate lysis buffer were essential in order to avoid sample degradation. Prolong homogenization procedure would heat up the samples and speed up the degradation process. Increased lysis buffer has enhanced the lysis process of the samples and simultaneously reduced the time of disruption and homogenization procedure. It is said that RNA is extremely labile and the crucial steps to maintain its stability proceed from sample collection, tissue disruption and process [29]. The homogenization step should be as short as possible and using plastic disposable probe was recommended compared with metal probe to preserve intact proteins and avoid degradation [16].

Protein concentration showed no significant differences either in fresh or stabilized tissues proved that the protein concentration did not easily degraded if proper handling and processing were considered. Significant biological and technical challenges in which differ in handling and processing are affected by the source of the tissue samples [30]. For human tissues which are obtained from biopsies and from autopsies, timing of harvest and initial handling of samples largely cannot be controlled [30]. Other than that, mincing or homogenizing the protein would be helpful for efficient protein release so that the surface exposed to solvent is enlarged [27]. However, strong and prolong homogenization might cause protein degradation as well and optimizations are important.

$R^{2}$ value was determined in order to confirm how closely our data conform to a linear relationship. $\mathrm{R}^{2}=1$ means that the graph would be perfect and the values obtained from the equation are accepted and mostly accurate. Protein concentration was good either form fresh or stabilized tissue. Successful protein extraction from different tissue types; fixed or unfixed tissue and validation methods have been approved from previous studies [17]. Purity of protein was qualitatively measured based on SDS-PAGE and Coomassie Blue staining. Measurement depends on the protein separation and its size. It showed that no qualitative differences between fresh and stabilized tissue in which the approximate size of the protein of interest was $30 \mathrm{kD}$. Other approaches are necessary in order to determine exactly the band of protein of interest are Western blot and mass spectrometry [30].

Slight difference in normal and CLP tissue has revealed the changes occurred in the lip tissue formation. However, staining procedure might necessary to get clear observations of the tissue morphology changes. Since RNA is labile, the immediate use of fresh tissue is recommended in order to get higher yields. However, there was no crucial issue of protein extraction, degradation or concentration. These proteins can be used for further analysis. 


\section{References}

1. Elisabeth M, Heiko R, Stefanie B, et al. Genome-Wide Linkage Scan of Nonsyndromic Orofacial Clefting in 91 Families of Central European Origin. Am J Med Genet. 2009: 149A: 2680-94.

2. Liu J, Lamme EN, Steegers-Theunissen RPM, et al. Cleft palate cells can regenerate a palatal mucosa in vitro. J Dent Res. 2008: 87(8): 788-92.

3. Blanton $\mathrm{SH}$, Amber B, Elizabeth $\mathrm{G}$, et al. Ethnic heterogeneity of IRF6 AP-2 $\alpha$ binding site promoter SNP association with nonsyndromic cleft lip and palate. Cleft Palate Craniofac J. 2010 47(6): 574-77

4. Scapoli L, Palmieri A, Martinelli M, et al. Strong evidence of linkage disequilibrium between polymorphisms at the IRF6 locus and nonsyndromic cleft lip with or without cleft palate, in an Italian population. Am J Hum Genet. 2005: 76: 180-83.

5. Hart TC, Marazita MC, Wright JC. The impact of molecular genetic on oral health paradigms. Critical Review Oral Biology Med. 2000: 11: 25-56.

6. Girardi A, Martinelli M, Carinci F, et al. No evidence for a role of CRISPLD2 in non-syndromic cleft lip with or without cleft palate in an Italian population. Eur J Oral Sci. 2011: 119: 102-05.

7. Lace B, Kempa I, Piekuse L, et al. Association studies of candidate genes and cleft lip and palate taking into consideration geographical origin. Eur J Oral Sci. 2011: 119: 413-17.

8. Bueno DF, Sunaga DY, Kobayashi GS, et al. Human stem cell cultures from cleft lip/palate patients show enrichment of transcripts involved in extracellular matrix modeling by comparison to controls. Stem Cell Rev and Rep. 2011: 7: 446-57.

9. Pauws E, Stanier P. FGF signaling and SUMO modification: new players in the aetiology of cleft lip and/or palate. TRENDS in Genetics. 2007: 23(12): 631-40.

10. Jakobsen LP, Borup $\mathrm{R}$, Vestergaard $\mathrm{J}$, et al. Expression analyses of cleft lip and palate tissue point to a role for osteopontin and immune related factors in cleft lip and palate. Exp Mol Med. 2009: 41(2): 77-85

11. Millington PF, Brown IA. Scanning electron microscope studies of some internal surfaces of human skin. Zeitschrift fur Zellforschung und mikroskopische Anatomie. 1970: 106: 209-219.

12. Fan $\mathrm{H}$, Gulley ML. RNA extraction from fresh or frozen tissues. Methods in Molecular Medicine. 2011: 49: 11-14.

13. Srinivasan M, Sedmak D, Jewell S. Effect of fixatives and tissue processing on the content and integrity of nucleic acids. American Journal of Pathology. 2002: 161: 1961-71.

14. Badrul Hisham Y, McLachlan G, Vrettou C, Collie D Optimising the quality and integrity of RNA samples from bronchial airway tissues. AsPac J Mol Biol Biotechnol. 2011: 19(1): 19-27.

15. Micke $P$, Ohshima M, Tahmasebpoor $S$, et al. Biobanking of fresh frozen tissue: RNA is stable in nonfixed surgical specimens. Laboratory Investigation. 2006: 86: 202-11.

16. Qiagen. Allprotect Tissue Reagent Handbook, 2010:3-25

17. Gräntzdörffer I, Yumlu S, Gioeva Z et al Comparison of different tissue sampling methods for protein extraction from formalin-fixed and paraffin-embedded tissue specimens. Experimental and Molecular Pathology. 2010: 88: 190-96.

18. Chu WS, Liang Q, Liu J, et al. A nondestructive molecule extraction method allowing morphological and molecular analyses using a single tissue section. Laboratory Investigation. 2005: 85 : 1416-28.

19. Ikeda K, Monden $\mathrm{T}$, Kanoh $\mathrm{T}$, et al. Extraction and Analysis of Diagnostically Useful Proteins from Formalin-fixed, Paraffinembedded Tissue Sections. The Journal of Histochemistry \& Cytochemistry. 1998: 46(3): 397-403.

20. Guo T, Wang W, Rudnick PA, et al. Proteome Analysis of Microdissected Formalin-fixed and Paraffin-embedded Tissue
Specimens. J Histochem Cytochem. 2007: 55(7): 763-72.

21. Periayah $\mathrm{MH}$, Halim AS, Hussein $\mathrm{AR}$, et al. In vitro capacity of different grades of chitosan derivatives to induce platelet adhesion and aggregation. International Journal of Biological macromolecules. 2013: 52: 244-249.

22. Lim CK, Halim AS, Ismail Z, et al. In vitro evaluation of a biomedical-grade bilayer chitosan porous skin regenerating template as a potential dermal scaffold in skin tissue engineering. International Journal of Polymer Science. 2011: doi:10.1155/2011/645820

23. Epithelial tissues. http://www.botany.uwc.ac.za/sci_ed/ grade10/mammal/epithelial.htm. Accessed July 25, 2013.

24. Brown IA. Scanning electron microscopy of human dermal fibrous tissue. J Anat. 1972: 113(2): 159-68.

25. Sawhney RK, Howard J. Slow local movements of collagen fibers by fibroblasts drive the rapid global self-organization of collagen gels. J Cell Biol. 2002: 157(6): 1083-92.

26. Ericsson $C$, Nistér M. Protein extraction from solid tissue. Methods Mol Biol. 2011: 675: 307-12.

27. Mutter GL, Zahrieh D, Liu C, et al. Comparison of frozen and RNALater solid tissue storage methods for use in RNA expression microarrays. BMC Genomics. 2004: 5:88.

28. Smith C. Tools for optimal RNA prep: From homogenization and cell lysis to extraction and purification. Biocompare Web site. $\mathrm{http}$ ://www.biocompare.com/Editorial-Articles/41847-Tools-for-

Optimal-RNA-Prep-From-Homogenization-and-Cell-Lysis-toExtraction-and-Purification/. Accessed October 25, 2012.

29. Md. Mahiuddin A, Gardiner KJ. Preserving protein profiles in tissue samples: differing outcomes with and without heat stabilization. J Neurosci Methods. 2011: 196(1): 99-106.

30. Protein purity and identity. http://chem.winthrop.edu/faculty/ grossoehme/link_to_webpages/courses/chem525/identification.pdf. Accessed January 9, 2014 